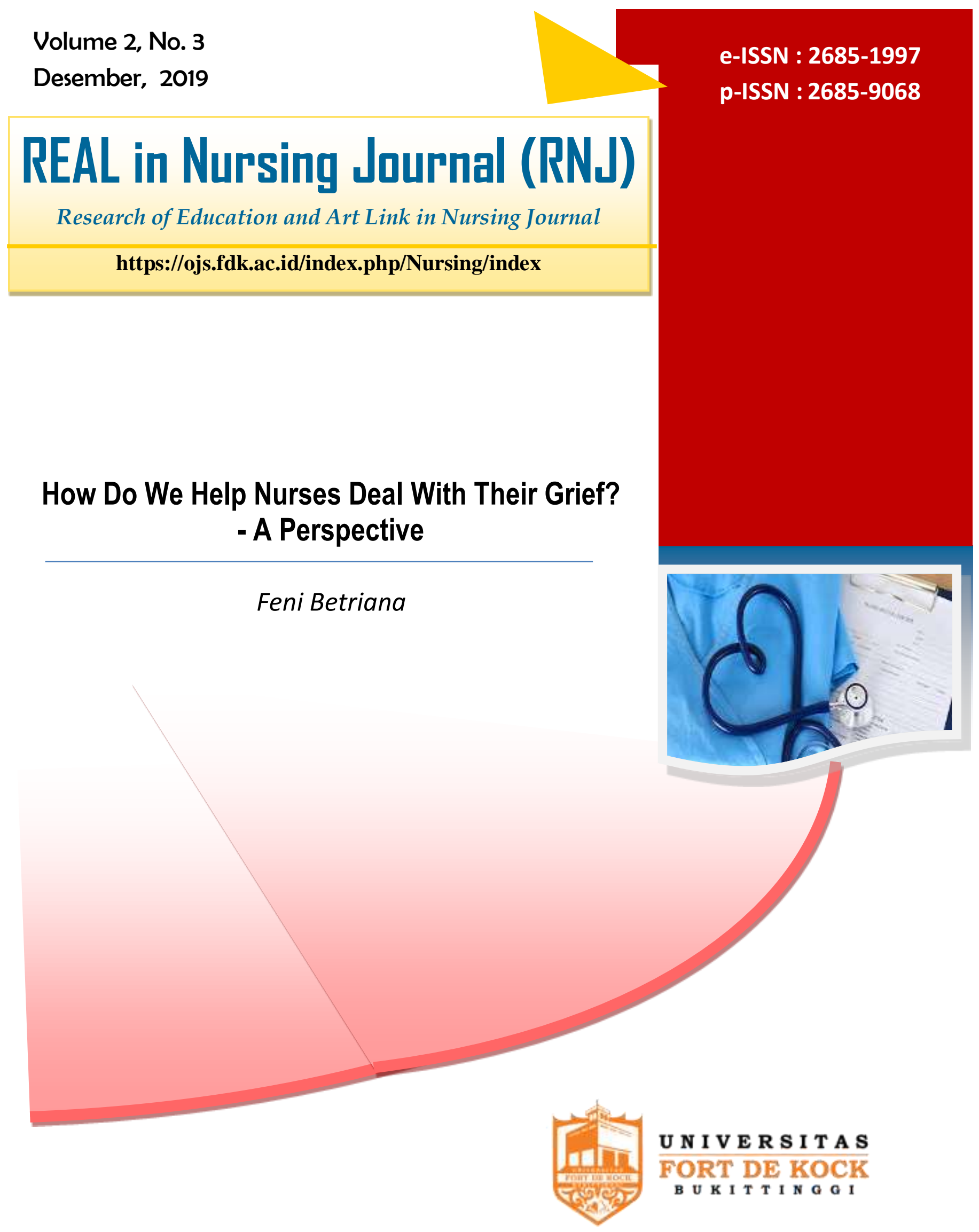

Program Studi Keperawatan dan Pendidikan Ners Universitas Fort de Kock Bukittinggi, Indonesia 


\section{How Do We Help Nurses Deal With Their Grief? - A Perspective}

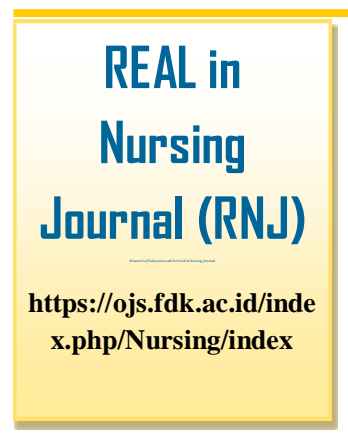

Keywords:

Nurse, grief

Korespondensi:

Feni Betriana

fenibetriana@gmail.com

Graduate School of Health
Sciences, Tokushima
University, Japan
Feni Betriana

\begin{abstract}
Nurses' grief has been subject to various studies. Being exposed to multiple dying and death of patients were reported to cause nurses ' grief. When the grief is not resolved well, this may lead to negative consequences which can affect nurses' physical and psychological well-being as well as the quality of nursing care. Nonetheless, attention to resolve nurses ' grief has not been paid well. Professional supports from institution are still limited and nurses mostly sought to find their own way to deal with their grief. This article aims to present a perspective on how to help nurses deal with their grief. One of the suggestions is to provide professional supports from institution, such as providing individual grief consultation, debriefing session, and retreat permission for nurses after dealing with patients' death.
\end{abstract}

Dying and death of patients are continuous events in healthcare setting. Even in the high technological situation, those are unavoidable and become parts of nurses' everyday work, especially in some units such as emergency department (ED), intensive care unit (ICU), high care unit (HCU), etc. Facing dying and death of patients were reported to cause nurses' grief (Shorter \& Stayt, 2009). In some cases, the grief may stay longer than it should be.

Grief is defined as a process due to losing Grief is defined as a process due to losing someone to death or response to such a loss (Zisook \& Shear, 2009). In the grieving process, normally people undergo the initial numbness leading to depression and finally to reorganization and recovery
(Zisook \& Shear, 2009). However, there are times when the grief is unresolved. Complicated grief is a term to describe the condition of unresolved and prolonged grief which can effect health, work, and social aspect (Zisook \& Shear, 2009).

Phenomenon of nurses grief occurs in many countries. A study exploring grief among Muslim nurses in an ICU in Indonesia revealed that nurses experienced grief in dealing with patients' death, which was expressed through several reactions such as feeling sad, disappointed, and feeling guilty (Betriana \& Kongsuwan, 2019a). Those reactions are related to several factors, including circumstances of patients' death, expectation of patients recovery, relationships with the patients, and 
reactions of patients' families (Betriana \& Kongsuwan, 2019a). Another study in Japan found that Japanese nurses experienced grief in dealing with patients' death related to the longer hospitalization and primary nursing care system (Shimoinaba, O'Connor, Lee, \& Kissane, 2014). In addition, a similar study investigating critical nurses in the ICU in the United Kingdom also revealed that nurse participants experienced feeling of grief for patients they had cared for (Shorter \& Stayt, 2009).

Even though nurses experience grief in dealing with patients' death, attention to resolve nurses' grief is not paid well. During academic preparation in nursing school, there is a lack of discussion about how to prepare nurses to deal with patient's death. Nursing curriculum includes end-of-life care but mostly focus on patients and families. This lack of discussion makes nursing students feel unprepared for patients' death when they graduate and eventually become nurses. In hospital, lack of awareness of nurses' grief often makes such grief is left unresolved. These conditions may affect their physical and psychological wellbeing.

Unresolved nurses' grief may result to several negative consequences include compassion fatigue, sleep disturbances, burnout, psychological and emotional stress (Betriana \& Kongsuwan, 2019b). To prevent these negative consequences as well as to maintain nurses' well-being and quality of nursing care, professional supports for nurses to deal with their grief are necessary.

\section{How do we help nurses deal with their grief?}

Helping nurses deal with their grief, especially the possible complicated grief, involves many parties, including nurses themselves, nurse managers, and institutions. Discussion about how to prepare nurses to face multiple death of patients should be started from nursing school. Subject/course about end-of-life care or palliative care should not only focus on patient's care and families, but also involve discussion about nurses' grief. Developing the understanding of the grieving and coping processes among nurses is critical (Gerow et al., 2010). Nurses need to acknowledge and embrace their grief in order for them to understand their grief situation and the need for professional supports.

Furthermore, nurse managers need to identify their nursing staff who are vulnerable for complicated grief thereby providing debriefing support for their staffs. Institution are suggested to provide education, counseling, and opportunities for nurses to grieve (Houck, 2014). Institution plays important role in providing professional support through policies. Such policies have been realized in some places. As examples, in the United States of America, the local organization called Good Grief Center is invited to a hospital every month for holding workshops in which nurses can meet and talk about healthy grieving (Brown, 2009). The hospital also pays nurses to have individual sessions at the Good Grief Center in case further consultation is needed (Brown, 2009). In other place such as Johns Hopkins Children's Care, bereavement debriefing sessions were 
offered to support health care professionals after experiencing patient's deaths (Keene, Hutton, Hall, \& Rushton, 2010). Necessary retreat for nurses after patient's death can also be provided by institutions. Retreat has been used as an intervention to address psychological toll and promote emotional renewal among oncology nurses (Aycock \& Boyle, 2009). In term of grief, retreat may give time for nurses to grieve and release emotional burden from patients' death.

To date, there are many studies exploring nurses' grief experiences in dealing with dying and death. We learn that nurses experience the grief and need help to deal with their grief. In some places, the institutions improved their policies to help their nursing staff to resolve their grief. However, in some other places, professional supports from institutions are still limited. Some questions remain, which may take place in your institution, "do the policies to support nurses' grief exist? Have the institutional supports to resolve nurses' grief been provided? Or do the situations stay the same, nurses seek for their own way to support themselves?".

\section{References}

Aycock, N., \& Boyle, D. (2009). Interventions to manage compassion fatigue in oncology nursing. Clinical Journal of Oncology Nursing, 13(2), 183-191. https://doi.org/10.1188/09.CJON.183-191

Betriana, F., \& Kongsuwan, W. (2019a). Grief reactions and coping strategies of Muslim nurses dealing with death. Nursing in Critical

Care. https://doi.org/10.1111/nicc.12481

Betriana, F., \& Kongsuwan, W. (2019b).
Nurses' grief in caring for patients with advanced cancer: A literature review. Songklanagarind Journal of Nursing, 39(1), 138-148.

Brown, T. (2009). Good Grief, Nurse Brown. Retrieved December 9, 2019, from The New York Times website: https://well.blogs.nytimes.com/2009/04/01 /helping-nurses-cope-with-grief/

Gerow, L., Conejo, P., Alonzo, A., Davis, N., Rodgers, S., \& Domian, E. (2010). Creating a curtain of protection: Nurses' experiences of grief following patient death. Journal of Nursing Scholarship, 42(2),

122-129.

https://doi.org/10.1111/j.1547-

5069.2010.01343.x

Houck, D. (2014). Helping nurses cope with grief and compassion fatigue: An educational intervention. Clinical Journal of Oncology Nursing, 18(4), 454-458. https://doi.org/10.1188/14.CJON.454-458

Keene, E. A., Hutton, N., Hall, B., \& Rushton, C. (2010). Bereavement debriefing sessions: an intervention to support health care professionals in managing their grief after the death of a patient. Pediatric Nursing, 36(4), 185-189.

Shimoinaba, K., O'Connor, M., Lee, S., \& Kissane, D. (2014). Losses experienced by Japanese nurses and the way they grieve. Journal of Hospice \& Palliative Nursing, 16(4) https://doi.org/10.1097/NJH.00000000000 00048

Shorter, M., \& Stayt, L. C. (2009). Critical care nurses' experiences of grief in an adult intensive care unit. Journal of Advanced Nursing, 66(1), 159-167. https://doi.org/10.1111/j.13652648.2009.05191.x

Zisook, S., \& Shear, K. (2009). Grief and bereavement: what psychiatrists need to know. World Psychiatry, 8(2), 67-74. 